\title{
Gastos de traslado, médicos, en equidad, procesales según las sentencias de la Corte Interamericana de Derechos Humanos.
}

\section{Transfer, medical, in fairness, procedural expenses, according to the judgments of the Inter-American Court of human rights.}

\section{RESUMEN}

El artículo estudia un tema de suma importancia y relevancia, en materia de reparaciones e indemnizaciones como son los gastos, señalados en las Resoluciones que emite la Corte Interamericana, cuya finalidad es resarcir el daño económico y material que sufrió la víctima y/ o sus familiares, por los actos del Estado.

De esta manera, el artículo permitirá entender a qué se refiere cada uno de estos gastos,que la Corte Interamericana de Derechos Humanos autoriza y ordena ante el Sistema Interamericano de protección de derechos humanos; como son los gastos de Equidad; Médicos; Necesarios; Razonables, de Traslados, Extrajudiciales y de Apreciación prudente, entre otros.

\section{PALABRAS CLAVE}

Gastos de traslado, gastos médicos, gastos en equidad, gastos procesales, Corte Interamericana de Derechos Humanos.

\section{ABSTRACT}

The article examines an issue of utmost importance and relevance, on reparations and indemnities as are the expenses mentioned in the resolutions issued by the Inter-American Court, which aims to redress the economic and material damage suffered by the victim and/ or their relatives for government actions.

Thus, Article allow you to understand what you mean each of these expenses, the Inter-American Court of Human Rights authorized and directed to the inter-American system of human rights protection; such as the cost of equity; doctors; required; Reasonable Movement, Extrajudicial and prudentestimate, among others.

\section{KEYWORDS}

Relocation expenses, medical expenses, equity, procedural costs, Inter-American Court of Human Rights. 


\section{INTRODUCCIÓN}

El Sistema Interamericano constituye el marco para la promoción y protección de los derechos humanos, y provee un medio de impugnación a los habitantes de América Latina que han sufrido violación de sus derechos humanos por parte del Estado. Los pilares del sistema son: la Comisión Interamericana de Derechos Humanos $(\mathrm{CIDH})$ con sede en la ciudad de Washington D.C. y la Corte Interamericana de Derechos Humanos (ColDH), con sede en San José de Costa Rica (Caso Suárez Rosero Vs. Ecuador).

El procedimiento ante la Corte es de carácter contradictorio. Termina con una Sentencia motivada, obligatoria, definitiva e inapelable. Si el fallo no expresa en todo o en parte la opinión unánime de los jueces, cualquiera de estos tiene derecho a que se agregue al fallo su opinión disidente o individual.

La reparación es el término genérico que comprende las diferentes formas como un Estado puede hacer frente a la responsabilidad internacional en que ha incurrido (restitutio in integrum, indemnización, satisfacción, garantías de no repetición, entre otras).

Las Resoluciones que emite la Corte Interamericana, en materia de reparaciones e indemnizaciones, son con la finalidad de resarcir el daño económico y material que sufrió la víctima $y / 0$ sus familiares, por los actos del Estado, Estados que tendrán que apegarse y acatar las resoluciones y medidas que estime necesarias y pertinentes el Sistema Interamericano en relación a la indemnización y reparación de gastos, los cuales son clasificados por la Corte Interamericana, la cual fijará los montos que ha de pagar el Estado a las víctimas basando sus sentencias/resoluciones, en las pruebas que se aporten durante el proceso, las cuales deberán de estar relacionadas con el Caso especifico tomando en consideración las característica particulares.

El tema que se expondrá es de suma importancia y relevancia ya que a lo largo de la historia y con mayor fuerza los últimos años los gastos, se han vuelto un tema crucial y preponderantemente importante en materia de reparación e indemnizaciones. La jurisprudencia de la Corte Interamericana de Derechos Humanos, establece diferentes tipos de Gastos como lo son aquellos que se realizan ante el Sistema Interamericano de protección de derechos humanos; los gastos de Equidad; Médicos; Necesarios; Razonables, de Traslados, Extrajudiciales y de Apreciación prudente, entre otros, los cuales con base tanto, en las jurisprudencias emitida por la Corte Interamericana, como en los procesos de los que tiene conocimiento y resuelve, permitirá entender a qué se refiere cada uno de ellos, mediante los cuales autoriza y ordena el pago de gastos.

\section{PRESUPUESTOS}

A continuación, se expondrán temas relacionados con los "Gastos" como es su fundamento en la Convención Americana, fundamento, Artículo 63, párrafo 10. Ahí mismo analizamos los precedentes para su aplicación; la responsabilidad internacional y de manera especifica restitutio in integrum; el fundamento de los "gastos" en el Reglamento Interno de la ColDH, artículo 65, párrafo 1, inciso h); y el daño patrimonial.

\subsection{Convención Americana}

Las reparaciones (Caso Garrido y Baigorria Vs. Argentina) ${ }^{1}$ se fundan en la Convención Americana de Derechos Humanos, en el artículo 63, párrafo $1^{\circ}$, prevé, lo siguiente:

$1^{\circ}$. Cuando decida que hubo violación de un derecho o libertad protegidos en esta Convención, la Corte dispondrá que se garantice al lesionado en el goce de su derecho o libertad conculcados. Dispondrá asimismo, si ello fuera procedente, que se reparen las consecuencias de la medida 0 situación que ha configurado la vulneración de esos derechos y el pago de una justa indemnización a la parte lesionada (Artículo 63).

1.- Sentencia del 27 de agosto de 1998, párrafo 39. 


\subsubsection{Precedentes}

La Corte interamericana tiene la facultad de valorar libremente las pruebas presentadas para la reparación y el pago de los gastos (erogaciones monetarias) que se realizaron, desde su defensa interna hasta los gastos realizados ante la Corte Interamericana, la valoración de las pruebas se realizará allegando casos en los cuales la Corte Interamericana ha sido parte y sobre las resoluciones y sentencias anteriormente emitidas, esto con la finalidad de establecer una reparación justa, equitativa y necesaria a las víctimas, familiares y abogados que tengan relación directa en el proceso, para reparar el detrimento económico que sufrió el patrimonio durante el proceso.

\subsection{Responsabilidad internacional}

Como la Corte lo ha indicado (Caso Aloeboetoe y otros) $)^{2}$, este artículo reproduce el texto de una norma consuetudinaria que constituye uno de los principios fundamentales del actual derecho internacional de la responsabilidad de los Estados ${ }^{3}$. Al producirse un hecho ilícito imputable a un Estado, surge responsabilidad internacional de éste por violación de una norma internacional. Con motivo de esta responsabilidad nace para el Estado una relación jurídica nueva que consiste en la obligación de reparar.

Todo gasto erogado tendrá sus peculiaridades, por ello la Corte Interamericana deberá de resolver en base a la aportación correspondiente de pruebas y a los criterios previamente establecidos, si es proce- dente 0 no el pago de gastos y las cantidades que debe de contemplar dicha reparación. No se comprenderán entre los gastos, las erogaciones monetarias de índole banal, claramente innecesarias, así como todos aquellos gastos prohibidos por la ley, y contrarios a la ética y las buenas costumbres.

\subsubsection{Restitutio in integrum, responsabilidad internacional.}

Al producirse un hecho ilícito imputable a un Estado, surge responsabilidad Internacional de éste por la violación de una norma internacional, con el consecuente deber de reparación. La reparación es el término genérico que comprende las diferentes formas como un Estado puede hacer frente a la responsabilidad internacional en que ha incurrido (restitutio in integrum, indemnización, satisfacción, garantías de no repetición, entre otras). La obligación de reparación establecida por los tribunales internacionales se rige, como universalmente ha sido aceptado, por el derecho internacional en todos sus aspectos: su alcance, su naturaleza, sus modalidades y la determinación de los beneficiarios, nada de lo cual puede ser modificado por el Estado obligado invocando para ello disposiciones de su derecho interno (Caso Loayza Tamayo Vs. Perú).

\subsection{Reglamento de la CoIDH}

En el Reglamento de la Corte Interamericana de Derechos Humanos se prevé que la Corte debe en las sentencias pronunciarse sobre las costas, si

2.- Reparaciones (art. 63.1 Convención Americana sobre Derechos), Sentencia de 10 de septiembre de 1993. Serie C No. 15, párr. 43.

3.- Cfr.: Usine de Chorzów, compétence, arręt no. 8, 1927, C.P.J.I. série A, no. 9, p. 21 y Usine de Chorzów, fond, arręt no. 13, 1928, C.P.J.I. série A, no. 17, p. 29; Reparation for Injuries Suffered in the Service of the United Nations, Advisory Opinion, I.C.J. Reports 1949, p. 184). Así lo ha aplicado esta Corte (Caso Velásquez Rodríguez, Indemnización Compensatoria, Sentencia de 21 de julio de 1989, (art. 63.1 Convención Americana sobre Derechos). Serie C No. 7, párr. 25; Caso Godínez Cruz, Indemnización Compensatoria, Sentencia de 21 de julio de 1989, (art. 63.1 Convención Americana sobre Derechos 11 Humanos). Serie C No. 8, párr. 23; Caso El Amparo, Reparaciones (art. 63.1 Convención Americana sobre Derechos), Sentencia de 14 de septiembre de 1996. Serie C No. 28, párr. 14); Caso Neira Alegría y otros, Reparaciones (art. 63.1 Convención Americana sobre Derechos), Sentencia de 19 de septiembre de 1996. Serie C No. 29, párr. 36; Caso Caballero Delgado y Santana, Reparaciones (art. 63.1 Convención Americana sobre Derechos), Sentencia 29 de enero de 1997. Serie CNo. 31, párr. 15). La jurisprudencia ha considerado también que la responsabilidad consagrada en esta disposición es un corolario necesario del derecho (sentencia arbitral de Max Huber del 23.X.1924 en el caso de los bienes británicos en Marruecos español, O.N.U., Recueil des sentences arbitrales, vol. II, p. 641; Barcelona Traction, Light and Power Company, Limited, deuxičme phase, arręt, C.I.J. Recueil 1970, p. 33. 
estas proceden, en los siguientes términos:

Artículo 65. Contenido de las sentencias

1. La sentencia contendrá:

a. el nombre de quien preside la Corte y de los demás Jueces que la hubieren dictado, del Secretario y del Secretario Adjunto;

(...)

h. el pronunciamiento sobre las reparaciones y costas, si procede;

Del texto anterior, podemos observar, que se prevé su pronunciamiento sobre las costas, solamente en los casos que proceda, aunque no dice nada sobre su determinación.

\subsection{Daño}

Las reparaciones se requieren por el daño provocado. El Criterio sostenido por la Corte Interamericana por Daño patrimonial, es el siguiente ${ }^{4}$ :

99. La Corte considera además que, no es posible establecer un nexo causal entre el hecho y las supuestas consecuencias que sufrió el hermano German Giovanni en cuanto a su ocupación y preparación académica; no obstante, este Tribunal considera que en términos reales, existió un daño patrimonial general ocasionado al grupo familiar por lo sucedido a la víctima, por motivos imputables al Estado, lo cual generó a la familia trastornos económicos, de salud y de otra índole, que deben ser reparados en equidad.

5. Que el Estado de Guatemala debe pagar, por equidad, como reintegro de los gastos y costas generados en la jurisdicción interamericana, la cantidad de US $\$ 20.000,00$ (veinte mil dólares de los Estados Unidos de América) al abogado Mark Martel, representante de los familiares de las víctimas Anna Elizabeth Paniagua Morales, Oscar Vásquez y Manuel de Jesús González López; al abogado René Argueta Beltrán, representante de los familiares de Erick Leonardo Chinchilla y Pablo Corado Barrientos la cantidad de US\$2.000,00 (dos mil dólares de los Estados Unidos de América); y al abogado Avilio
Carrillo Martínez, representante de los familiares de William Otilio González Rivera, la cantidad de US $\$ 1.000,00$ (un mil dólares de los Estados Unidos de América) (Caso Paniagua Morales y otros Vs. Guatemala).

Respecto al punto de equidad en los gastos, se plantea que el juzgador al momento de realizar la partición de las costas le debe dar a cada uno lo que le corresponde como reintegro de los gastos realizados para acudir al Sistema Interamericano.

\section{GASTOS: DIFERENCIAS Y TIPOS}

A continuación se expondran los "Gastos", en dos partes, primero las diferencias; y luego los cinco tipos de gastos. En la primera parte presentamos los "Gastos", su diferencia con las costas y la forma de determinación. En los tipos de gastos, exponemos los gastos de traslado, médicos, necesarios y razonables, de apreciación prudente, en equidad y los judiciales, procesales y extrajudiciales. En el caso de los gastos médicos, exponemos aquellos realizados por tratamientos quirúrgicos; el caso en el que las pruebas no fueron desvirtuadas en el juicio, así como el caso de aquellos gastos médicos que no se presentaron pruebas, los gastos médicos realizados en el caso de desaparición forzada de persona y los gastos médicos futuros.

\subsection{Gastos: gastos y costas}

\subsubsection{Gastos}

El reclamo judicial de los gastos, presupone necesariamente el desahogo de las pruebas pertinentes y demostrativas consecutivas de causa a efecto, así como la cuantía a que ascendió, pues sin ninguna probanza de las erogaciones realizadas no es dable llegar a la compensación por ello es necesario el desahogo de pruebas correspondientes las que dependerán del tipo de gasto, que en su momento y oportuno tiempo la Corte Interamericana valorara con la finalidad de establecer el monto y fijar

4.- ColDH sentencia del 25 de mayo de 2001, párrafo 99 y resolutivo 5. 
si la reparación por concepto de Gastos es fundada o no.

\subsubsection{Gastos, determinación}

Para determinar si los gastos son o no necesarios los jueces gozan de un prudente arbitro, contando para ello con las pruebas necesarias y pertinentes para que se autorice el cobro respectivo por concepto de gastos. Los gastos no pueden ir más allá de los que se origine durante el proceso y aquellos que pudieran generar erogaciones significativas posteriores al término del juicio correspondiente. De tal modo se allegarán de las resoluciones anteriores para poder argumentar sus actuaciones.

\subsubsection{Acto jurisdiccional: apreciación prudente}

Corresponde entonces a la Corte Interamericana, en ejercicio de su poder jurisdiccional, apreciar prudentemente el alcance específico de los gastos sobre los que versa las sentencia, así mismo sobre las costas que en este sentido se entiende como gastos derogados ante el Sistema Interamericano; apreciación prudente; gastos extrajudiciales; gastos necesarios; gastos razonables; y de traslado, tomando en cuenta: a) la oportuna comprobación de las mismas, b) las circunstancias del caso concreto, c) la naturaleza de la jurisdicción de protección de los derechos humanos; d) las características del respectivo procedimiento, e) atendiendo a los rasgos específicos de los cuales revistió este proceso, tanto de carácter nacional como internacional.

Por todo lo anterior es de vital importancia el pago de gastos, ya que significa la restitución monetaria del detrimento causado a las víctimas siguientes: a) familiares, b) derecho habientes y c) apoderados legales en su patrimonio, motivado por la necesidad de acceder a la protección de la Corte Interamericana cuya finalidad es resarcir en la medida de lo posible los daños económicos que sufrieron durante el proceso, de los cuales el Estado es responsable.

\subsubsection{Gastos y costas. Concepto}

Los gastos se relaciona en paralelo con las "Costas", por ello se entiende como gastos el lucro que sufre en su patrimonio económico, como consecuencia directa del juicio. Todas las erogaciones monetarias que se realizan desde el momento que se inicia el juicio hasta que se termina, los cuales han de tener una relación directa con el proceso, cuya finalidad es reparar el detrimento económico que sufrió la víctima, los beneficiarios y el pago de costas correspondientes a sus representantes legales.

\subsubsection{Costas, tipos}

Las costas son erogaciones que las partes efectúan con motivo del proceso y pueden dividirse en judiciales y procesales. El diccionario de la Real Academia Española, vigésima segunda edición, 2012, define a los "gastos [como aquellos] relacionados con un proceso".

\subsection{Tipos de Gastos}

A continuación vamos exponer los distintos tipos de gastos, como los siguientes: gastos de traslado; gastos médicos; gastos necesarios, razonables y de apreciación prudente; y gastos judiciales, procesales yextrajudiciales.

\subsubsection{Gastos de traslado}

Son las erogaciones de índole monetario correspondientes al pago de transportación ya sea aérea y terrestre, tanto de los familiares como de los abogados.

Gastos de traslado (Caso Loayza Tamayo Vs. Perú $)^{5}$

c) una suma correspondiente a los gastos de traslado de los familiares para visitar a la víctima durante su encarcelamiento. La Corte considera 
pertinente otorgar, en equidad, un monto de US\$ 500,00 (quinientos dólares de los Estados Unidos de América) por las erogaciones relacionadas con este rubro (....) (Párrafo 129, inciso c).

De la anterior, podemos afirmar que como gastos de traslado se refiere a todas y cada una de las erogaciones de índole monetaria correspondientes al pago de transportación ya sea aérea y terrestre, tanto de los familiares como de los abogados.

\subsubsection{Gastos médicos}

Se consideran gastos médicos todas aquellas erogaciones realizadas por parte de la víctima o sus familiares con la finalidad de mantener en optimas condiciones la salud, la cual sufre una afectación real y notable en diversos casos: i). Tratamiento médico provocados por detención ilegal y flagelaciones contra la víctima; ii). En los casos cuyo fin es el de curar los padecimientos generados durante el proceso originado por el actuar negligente y arbitrario del Estado, gastos cubiertos por la víctima dado el decadente sistema médico con él que cuenta el sistema penitenciario y/o carcelario dentro de sus instalaciones; iii). Todas aquellas erogaciones realizadas por la parte lesionada a fin de curar los padecimientos generados por la impotencia ante la falta de resultados de las investigaciones de los hechos por parte de las autoridades públicas.

Los gastos médicos los vamos analizar en el orden siguiente: i). Por tratamientos quirúrgicos; ii). Por gastos realizados que en el juicio las pruebas no fueron desvirtuadas; iii). Por gastos realizados pero que no se tienen pruebas; iv). Por gastos médicos realizados en caso de desaparición forzada de persona; v). y por gastos médicos futuros.

\subsubsection{Gastos médicos por tratamiento quirúrgico}

La Corte Interamericana ordena el pago de gastos y costas sobre el rubro a nivel médico y de traslado, a favor del actor, su esposa e hija, en atención a las afectaciones que sufrieron. En el Caso que analizamos, se observa que en la parte conducente los gastos médicos surgen de la necesidad de resarcir la pérdida económica sufrida a consecuencia de un tratamiento médico quirúrgico realizado a causa de algún accidente o enfermedad, como se comentó, se presentó a causa de la ilegal detención y flagelaciones en contra del actor.

Hecho que repercutió, en la vida cotidiana de la esposa del demandante, lo que provoco un menoscabo en su salud y en el gravamen en su discapacidad motriz, por lo que; se tuvo que atender con especialistas, así como hacerse a los servicios de una(s) personas, a efecto de que la apoyaran en el traslado de un lugar a otro. Por lo anterior, la Corte Interamericana califica a los primeros como gastos y/o costas de tipo médico y a las segundas como de traslado. Entendiendo que las primeras están encaminadas a atender cuestiones físicas 0 psicológicas, mientras las segundas cubren el rubro de la movilidad, no solo nacional sino también a nivel internacional. Derivado de lo anterior, la Comisión Interamericana resuelve a favor del actor y sus demás beneficiarios, para los efectos a los que se refiere esta sentencia en su rubro de gastos y costos médicos y por traslado. (Caso Suárez Rosero Vs. Ecuador).

\subsubsection{Pruebas no desvirtuadas}

La Corte Interamericana de Derechos Humanos sostiene los tipos de gastos que hace alusión la sentencia del caso, Loayza Tamayo Vs. Perú, sobre reparaciones y costas.

129. Teniendo presentes la información recibida, su jurisprudencia y los hechos probados, la Corte declara que la indemnización por daño material en el presente caso debe comprender los siguientes rubros:...

\section{1.- Gastos Médicos:}

b) una suma correspondiente a los gastos médicos de la víctima durante su encarcelamiento, pues la Corte considera que existe evidencia suficiente que demuestra que los respectivos padecimientos se 
originaron en su reclusión y este hecho no ha sido desvirtuado por el Estado. La prueba presentada para respaldar el cálculo hecho por la víctima a este respecto no es concluyente y la Corte considera pertinente otorgar, en equidad, un monto de US\$ 1.000,00 (mil Dólares de los Estados Unidos de América) por las erogaciones relacionadas con este rubro) (Caso Loayza Tamayo Vs. Perú, párrafo 129, inciso b).

La Corte Interamericana para fijar la reparación por los gastos médicos del caso anterior, las determinó a partir de dos elementos: i). Las pruebas originadas por el padecimiento de la reclusión, y; ii). La actuación del Estado al no desvirtuar las pruebas presentadas.

\subsubsection{Pruebas, falta de sustento.}

La Corte Interamericana determina los gastos médicos, no obstante la ausencia de suficientes elementos probatorios, en el caso siguiente:

3.- Gastos Médicos.

97. María Ildefonsa Morales de Paniagua, en sus testimonios tanto en el fondo como en esta fase de reparaciones, indicó que sufrió diversas enfermedades como resultado de la muerte de su hija, las cuales requirieron de tratamientos médicos; sin embargo, no aportó elementos probatorios.

119. Asimismo, se ha solicitado el resarcimiento de los gastos sufragados por los familiares de Julián Salomón Gómez Ayala, para su exhumación; del correspondiente traslado de sus restos a "Samayach"; los gastos por el funeral; la pérdida de efectos personales, tales como una medalla de oro, y los gastos médicos en que incurrieron los padres, como resultado de lo sucedido a la víctima. La Corte considera que, en términos reales, existió un daño patrimonial general ocasionado al grupo familiar por lo sucedido a la víctima, por motivos imputables al Estado, lo cual generó a la familia trastornos económicos y de otra índole que deben ser reparados. En el caso subjudice la Corte observa que las peticiones de la familia respecto de los gastos carecen de soporte documental; sin embargo, tomando en cuenta las circunstancias del caso, parecería razonable que no exista, elementos probatorios suficientes. Por lo expuesto, el Tribunal fija, equitativamente, la cantidad de US $\$ 3.000,00$ (tres mil dólares de los Estados Unidos de América).

120. En razón de las circunstancias especiales de este caso, este Tribunal considera pertinente distribuir dicha cantidad en partes iguales entre sus padres Petronilo Gómez Chávez y Blanca Esperanza Ayala de la Cruz- y su compañera - Bertha Violeta Flores Gómez-

136. Salvador González Najarro, en su testimonio en esta fase de reparaciones, indicó que, como resultado de la muerte de su hijo, su esposa María Asunción Rivera Velásquez y él han sufrido una serie de enfermedades, que requirieron de tratamientos médicos, pero, no existe un sustento probatorio sobre este punto (...) (Caso Paniagua Morales y otros Vs. Guatemala, párrafos $97,119,12$ y 136)

Es importante resaltar, en el criterio jurisprudencial citado, la ausencia suficiente de pruebas de gastos, por lo que respecta al pago de gastos médicos a la parte lesionada, el juzgador antes de decretar su pago, requiere que la parte en cuestión acredite la erogación reclamada, en caso contrario, deberá liberar al Estado de dicho reclamo, no obstante, por considerar el juzgador que hubo afectación patrimonial necesariamente fijo la reparación en una cantidad muy baja.

\subsubsection{En caso de la Desaparición forzada.}

En el caso de los gastos médicos que provocan padecimientos a las víctimas por desaparición forzada de una persona, el criterio jurisprudencial de la Corte Interamericana de Derechos Humanos es el siguiente:

Gastos Médicos: 50 . En lo que se refiere a la solicitud de que se ordene a Guatemala el pago de la cantidad de US $\$ 138.470,00$ (ciento treinta y ocho mil cuatrocientos setenta dólares de los Estados Unidos de América) por concepto del tratamiento médico recibido y por recibir del señor Samuel Blake, la Corte considera que se ha determinado que sus padecimientos se enmarcan en la situación de la desaparición de su hermano, la incertidumbre sobre su paradero, el sufrimiento al conocer su muerte, y su frustración e impotencia ante la falta de resultados de 
las investigaciones de los hechos por parte de las autoridades públicas guatemaltecas y su posterior encubrimiento. En razón de lo anterior, este Tribunal estima que es pertinente otorgar al señor Samuel Blake, en equidad, una cantidad de US $\$ 15.000,00$ (quince mil dólares de los Estados Unidos de América) por ese concepto, en calidad de integrante de la parte lesionada.

ii. US $\$ 15.000,00$ (quince mil dólares de los Estados Unidos de América) por concepto de gastos médicos en favor del señor Samuel Blake; ColDH. (Caso Blake Vs. Guatemala, párrafo 50 y numeral ii, del inciso a)

La Corte Interamericana considera gastos médicos todas aquellas erogaciones realizadas por la parte lesionada a fin de curar los padecimientos generados por i) la desaparición de su hermano, ii) la incertidumbre sobre su paradero, iii) el sufrimiento al conocer su muerte, iv) su frustración e impotencia ante la falta de resultados de las investigaciones de los hechos por parte de las autoridades públicas; y v) su posterior encubrimiento.

\subsubsection{Gastos médicos futuros en equidad.}

El reclamo judicial de los gastos médicos, presupone necesariamente el desahogo de las pruebas pertinentes, demostrativas de las alteraciones de la salud consecutivas de causa a efecto, así como la cuantía a que ascendió el tratamiento, pues sin ninguna probanza de las erogaciones realizadas no es dable llegar a la compensación.

A continuación exponemos el criterio jurisprudencial emitido por la Corte Interamericana relativo a gastos médicos futuros:

129. Gastos Médicos Futuros en Equidad. $\left(^{6}\right)$

(...)

d) una suma correspondiente a los gastos médicos futuros de la víctima y de sus hijos, pues la Corte considera que existe evidencia suficiente que demuestra sus padecimientos se originaron en la reclusión de la primera y este hecho no ha sido desvirtuado por el Estado. La Corte considera pertinente otorgar, en equidad un monto de US\$ 15.000,00 (quince mil dólares de los Estados Unidos de América) para la víctima y un monto de US\$ 5.000,00 (cinco mil dólares de los Estados Unidos de América) para cada uno de sus hijos.

VIII. Hechos probados durante la etapa de reparaciones $\left({ }^{7}\right)$

$106 \ldots$

c) la reclusión de su madre les provocó graves trastornos de salud psíquica, a raíz de los cuales requieren, en forma urgente, tratamiento médico idóneo (Cfr. dictámenes médicos emitidos por el Dr. René Flores Agreda, el 6 de octubre de 1998; declaración ante Notario de Giselle Elena Zambrano Loayza y declaración ante Notario de Paul Abelardo Zambrano Loayza).

Para el pago de gastos médicos futuros será necesario demostrar el daño psicológico que le causaron a los hijos de la víctima ya que la afectación sufrida por la arbitrariedad del actuar del Estado del Perú, origino una afectación significativa en el entorno social y familiar de los menores, recordemos que el Estado tiene la obligación de velar por salvaguardar y proteger el interés superior, por tal motivo y para que los menores se integren con libertad y seguridad a su núcleo social incluida la propia familia, necesitarán de profesionales capacitados (psicólogos y terapeutas) para que puedan alcanzar su bienestar psicológico, emocional ymental.

\subsection{Gastos de apreciación prudente y necesaria y razonable}

\subsubsection{Gastos de apreciación prudente}

La Corte Interamericana se refiere al quantum razonable de las costas realizadas por los familiares en erogación monetaria para que se lleve a cabo el proceso ante las instancias nacionales y del Sistema Interamericano teniendo en cuanta la "conexión suficiente" entre esos y el resultado obtenido, en los términos siguientes:

6.- CoIDH, Caso Loayza Tamayo Vs. Perú, sentencia 17 de septiembre de 1997, párrafo 106, inciso c).

7.- CoIDH, Caso Loayza Tamayo Vs. Perú, sentencia 17 de septiembre de 1997, párrafo 129, inciso b). 
Gastos: Apreciación Prudente. $\left.{ }^{8}\right)$

82. Desde luego, corresponde a la Corte, en el ejercicio de sus poderes jurisdiccionales, apreciar prudentemente el alcance específico de las costas sobre las que verse la condena, tomando en cuenta tanto la comprobación de las mismas que se haga oportunamente, como las circunstancias del caso concreto y la naturaleza de la jurisdicción de protección de los derechos humanos y las características del respectivo procedimiento, que poseen rasgos propios y diferentes de los que pudieran revestir 20 otros procesos, tanto de carácter nacional como internacional. La Corte determinará el quantum razonable de las costas realizadas por los familiares de las víctimas y sus abogados ante la Argentina, la Comisión Interamericana y ante esta Corte sobre una base equitativa y teniendo en cuenta la "conexión suficiente" entre aquéllas y los resultados alcanzados (cfr. Eur. Court H. R., Brincat v. Italy Judgment of 26 November, 1992, Series Ano. 249-A).

\subsubsection{Gastos necesarios y razonables}

Comprenden los diversos gastos que la víctima hace o se compromete a hacer para acceder al Sistema interamericano de protección de los derechos humanos, entre los que figuran los honorarios que ha de cubrir, convencionalmente, a quienes le brindan asistencia jurídica. Obviamente, se trata sólo de gastos necesarios y razonables, según las particularidades del caso y efectivamente realizados 0 causados a cargo de la víctima o sus representantes

Gastos Necesarios y Razonables:

80. En atención a las disposiciones aplicables y a la experiencia, la Corte considera que las costas a que se refiere el citado artículo 55.1 del Reglamento comprenden los diversos gastos que la víctima hace o se compromete a hacer para acceder al sistema interamericano de protección de los derechos humanos, entre los que figuran los honorarios que ha de cubrir, convencionalmente, a quienes le brindan asistencia jurídica. Obviamente, se trata sólo de gastos necesarios y razonables, según las particularidades del caso y efectivamente realizados 0 causados a cargo de la víctima o sus representantes. (Caso Garrido y Baigorria Vs. Argentina, párrafo 80).

\subsection{Gastos en equidad}

Son todos aquellos elementos para valorar las actuaciones en el proceso ante un tribunal internacional, el aporte de pruebas que tiendan a demostrar los hechos expuestos y las erogaciones monetarias que sufrió la víctima o sus derechohabientes así como sus representantes, el conocimiento acabado de la jurisprudencia internacional y, en general, todo aquello que permita evaluar la calidad y pertinencia de todo lo efectuado, se plantea que el juzgador al momento de realizar la partición de las costas le debe dar a cada uno lo que se merece.

\subsection{Gastos procesales y extrajudiciales}

A continuación exponemos i). Costas procesales y ii). Las extrajudiciales. Las costas procesales, es importante distinguirlas de las judiciales, a su vez las procesales se clasifican en las realizadas primero ante instancias internas y después ante, instancias internacionales, como ante el Sistema Interamericano, que comprenden ante la Comisión Interamericana y los realizados ante la Corte Interamericana.

\subsubsection{Costas Procesales}

Son todas aquellas que las partes realizan y que no se encuadran en las judiciales, como el pago de los servicios prestados por los peritos y abogados, publicación de edictos, etc. Hay que distinguir entre los gastos y las costas. La última expresión comprende únicamente los honorarios de los abogados y la primera todas las demás erogaciones legítimas susceptibles de ser comprobadas.

\subsubsection{Costas Judiciales}

Son aquellas que la ley establece como contribución fiscal para el pago de los servicios prestados por el Tribunal. En muchos países como en México, de conformidad con lo dispuesto por el artículo 17 de la Constitución Política de los Estados Unidos Mexicanos, el servicio de los tribunales de justica es gratuito y, por tanto, quedan prohibidas las "costas judiciales" (Contreras 2011, p. 269). 


\subsubsection{Gastos ante el Sistema Interamericano}

Se conforman por los gastos que derivan de la actividad desplegada por la víctima, sus derechohabientes 0 sus representantes para obtener la resolución jurisdiccional en la que se reconozca la violación cometida y se fijen sus consecuencias jurídicas. Dicho de otra manera, la actividad desplegada por aquéllos para acceder a la justicia que la Convención provee, implica o puede implicar erogaciones y compromisos de carácter económico que deben ser compensados a la víctima cuando se dicta sentencia condenatoria.

A continuación, exponemos criterios de la Corte Interamericana respecto de gastos que inician ante las instancias internas y llegan ante el Sistema Interamericano, pasando por los gastos generados ante la Comisión Interamericana y llegando a los generados ante la Corte Interamericana, en el Sistema Interamericano.

[Reparaciones: locus standi] 178. Es preciso observar que el artículo 23 del Reglamento permite a los representantes de las víctimas 0 de sus familiares presentar sus propios argumentos y pruebas en forma autónoma en la etapa de reparaciones ante esta Corte. Este reconocimiento del locus standi de aquellos abre la posibilidad de gastos asociados a dicha representación. En la práctica, la asistencia legal a la víctima no se inicia apenas en la etapa de reparaciones, sino que comienza ante los órganos judiciales nacionales y continúa en las sucesivas instancias del sistema interamericano de tutela de los derechos humanos, es decir, en los procedimientos que se siguen ante la Comisión y ante la Corte. Por ende, en el concepto de costas, para los fines que ahora se examinan, quedan comprendidas tanto las que corresponden a la etapa de acceso a la justicia a nivel nacional (Caso Garrido y Baigorria, Reparaciones, supra 84, párr. 81), como las que se refieren a la justicia a nivel internacional ante dos instancias: la Comisión y la Corte. (Caso Loayza Tamayo Vs. Perú, párrafos 174-180)

\section{Gastos ante instancias internas.}

Fijar en US $\$ 2.000,00$ (dos mil dólares de los Estados Unidos de América) o su equivalente en moneda nacional peruana, la suma que deberá pagar el
Estado a los familiares de las víctimas en concepto de reintegro de costas efectuadas en el derecho interno.

En el asunto que se estudia, se toca el tema de los gastos de equidad y desde el punto de vista interamericano, razón por la cual es pertinente acotar lo siguiente:

\section{Gastos o costas ante Sistema Interamericano.}

Si bien la Comisión Interamericana, condena al pago de una suma liquida a favor de los familiares del actor en atención a las vejaciones que sufrió, ésta misma Corte entra al estudio y clasificación de los gastos y costas que se generaron, no solo desde el inicio del procedimiento a nivel nacional, sino todo el camino que las mismas siguieron al dar el salto al campo internacional, es decir durante la etapa en la Comisión Interamericana, lo cual se traduce ya no en unas costas y/o gastos como comúnmente se conciben, sino que adquieren el status de gastos 0 costas ante el Sistema Interamericano.

Gastos de equidad. Por su parte los gastos de equidad, si bien no hay uniformidad en la doctrina y quizás, muy poca difusión de los casos únicos que se enlistan, se observa que provienen de la equivalencia entre el daño sufrido o las erogaciones que las partes aportan para el normal desarrollo del procedimiento y que por lo tanto los mismos deben ser resarcidos, sino a un tipo de cambio internacional como lo es el dólar americano, si se puede trasferir a su equivalente en la moneda nacional del lugar donde es nacional el actor, y a éstos se le conoce como, gastos o costas de equidad. (Caso Castillo Páez Vs. Perú, Sentencia de 27 de noviembre de 1998).

\subsubsection{Costas forman parte de las reparaciones: honorarios}

Acontinuación se expondrán los gastos procesales 0 costas que se ordena se comprendan dentro de las reparaciones que prevén la Convención, artículo 63.1; y el Reglamento Interior de la CoIDH, artículos 55.1 , inciso $h$ ) y artículo 23 , en beneficio de la víctima, sus derechohabientes 0 sus representantes, 
siguiente:

Gastos ante el Sistema Interamericano, necesarios y razonables $\left({ }^{9}\right)$ :

174. La Comisión solicitó que la Corte ordene el pago de los gastos en que incurrió Carolina Loayza Tamayo al asumir la defensa legal de la víctima ante los tribunales peruanos y los órganos del sistema interamericano, para lo cual se remitió a los fundamentos y cálculos de gastos presentados por la víctima en su escrito.

175. Al respecto, el Perú señaló que la Corte, en su sentencia de 17 de septiembre de 1997, resolvió que el Estado debía resarcir sólo los gastos en que efectivamente incurrieron los familiares de la víctima; que la señora Carolina Loayza Tamayo no había sido incluida como víctima por la Comisión y que no procedía ninguna solicitud a su favor. De acuerdo con el Perú, por estas razones, no serían admisibles las pretensiones de la víctima en esta etapa. Además, agregó que el fallo citado ordenó el resarcimiento de gastos ante las autoridades peruanas y no el pago de honorarios profesionales.

[Costas son parte de las reparaciones] 176. En relación con los anteriores planteamientos, la Corte estima que en el presente caso procede examinar la fijación de costas, en los términos del inciso h) del artículo 55.1 de su Reglamento. Las costas deben ser incluidas dentro del concepto de reparación al que se refiere el artículo 63.1 de la Convención, puesto que derivan naturalmente de la actividad desplegada por la víctima, sus derechohabientes o sus representantes para obtener la resolución jurisdiccional en la que se reconozca la violación cometida y se fijen sus consecuencias jurídicas. Dicho de otra manera, la actividad cumplida por aquellos para acceder a la justicia internacional implica o puede implicar erogaciones y compromisos de carácter económico que deben ser compensados a la víctima cuando se dicta sentencia condenatoria.

[Gastos: honorarios] 177. En atención a las disposiciones aplicables, la Corte considera que las costas a que se refiere el citado artículo 55.1 del Reglamento comprenden los diversos gastos que la víctima hace o se compromete a hacer para acceder al sistema interamericano de protección de los derechos humanos, entre los que figuran los honorarios que ha de cancelar, convencionalmente, a quienes le brindan asistencia jurídica. Obviamente, se trata sólo de gastos necesarios y razonables, según las particularidades del caso y efectivamente realizados o causados a cargo de la víctima o sus representantes (Caso Garrido y Baigorria, Reparaciones, supra 84, párr. 80).

180. Con base en lo anterior la Corte fija las costas y honorarios en la suma de US\$20.000,00 (veinte mil dólares de los Estados Unidos de América), de los cuales US\$ 15.000,00 (quince mil dólares de los Estados Unidos de América) corresponden a los honorarios de la abogada Carolina Loayza Tamayo. (Caso Loayza Tamayo Vs. Perú, párrafos 174-180)

La cantidad monetaria que se erogó fue para obtener el beneficio y ejercer la garantía judicial, y protección de los derechos humanos de la víctima y su justa defensa, en este caso se erogaron los gastos necesarios para su adecuada defensa en el proceso, lo que implicó en su momento gastos, ante el Sistema Interamericano, los necesarios y razonables, como son gastos de representación legal, copias certificadas, envíos, diligencias, etc. Es importante resaltar, el criterio de la Corte Interamericana, que contabiliza los gastos que son originados desde las instancias nacionales hasta la sentencia condenatoria de la Corte Interamericana.

La Corte Interamericana otorgará con base en la equidad y de acuerdo a las pruebas aportadas durante el proceso, y tomando en consideración casos anteriores, experiencia y jurisprudencia al respecto el monto que estime prudente y justo por gastos.

\section{Gastos. No objeciones de gastos.}

78. $\mathrm{Ni}$ el Estado argentino ni la Comisión Interamericana opusieron objeciones a lo expuesto por los familiares de las víctimas en cuanto a gastos efectuados. Sólo un juez de la Corte preguntó durante la audiencia sobre un gasto realizado, lo que fue explicado por el

9.- CoIDH, Caso Loayza Tamayo Vs. Perú, sentencia 17 de septiembre de 1997, párrafos 174-180. 
abogado Varela Álvarez. (Caso Garrido y Baigorria Vs. Argentina, párrafo 78)

\subsubsection{Costas procesales, reglas para fijarlas.}

Es importante resaltar las reglas que utiliza el juzgador para fijarla las costas y cuales no son métodos adecuados para fijarlos:

[Costas: reglas para fijarlas] 179. Corresponde entonces a la Corte, en ejercicio de su poder jurisdiccional, apreciar prudentemente el alcance específico de las costas sobre las que versa la condena, tomando en cuenta i) la oportuna comprobación de las mismas, ii)las circunstancias del caso concreto, iii) la naturaleza de la jurisdicción de protección de los derechos humanos y iv) las características del respectivo procedimiento, que poseen rasgos propios y diferentes de los que pudieran revestir otros procesos, tanto de v) carácter nacional como internacional. El monto razonable de las costas realizadas por la víctima o sus representantes y sus abogados ante el Perú, la Comisión Interamericana y ante este Tribunal será determinado sobre vi) una base equitativa (Caso Loayza Tamayo Vs. Perú, párrafos 174-180).

\section{Equidad.}

83. La Corte no estima adecuado que la regulación de costas deba guardar una proporción con el monto de la indemnización obtenida. Existen otros elementos que son más importantes para valorar la actuación de los abogados en un proceso ante un tribunal internacional, como, por ejemplo, el aporte de pruebas que tiendan a demostrar los hechos expuestos en la demanda, el conocimiento acabado de la jurisprudencia internacional y, en general, todo aquello que permita evaluar la calidad y pertinencia del trabajo efectuado.

84. Otra circunstancia que es preciso tomar en consideración para la regulación de honorarios de los señores Varela Alvarez y Lavado es que ellos compartieron la representación de los familiares de las víctimas con otros abogados durante las diferentes etapas desarrolladas, tanto en el derecho interno como ante los órganos interamericanos. (Caso Garrido y Baigorria Vs. Argentina, párrafo 83)

\subsubsection{Alcance de gastos.}

Corresponde entonces a la Corte, en ejercicio de su poder jurisdiccional, apreciar prudentemente el alcance específico de los gastos sobre los que versa la sentencia, así mismo sobre las costas que en este sentido se entiende como gastos derogados ante el Sistema Interamericano, apreciación prudente, extrajudiciales, necesarios, razonables y de traslado, tomando en cuenta la oportuna comprobación de las mismas, las circunstancias del caso concreto, la naturaleza de la jurisdicción de protección de los derechos humanos y las características del respectivo procedimiento, atendiendo a los rasgos específicos de los cuales revistió este proceso, tanto de carácter nacional como internacional. El monto razonable de las costas realizadas por la víctima 0 sus representantes y sus abogados ante el Estado responsable, la Comisión Interamericana y ante Tribunal Interamericano, el cual será determinado sobre una base equitativa, la cual se determino de acuerdo al caso específico; atendiendo a las particularidades del caso las averiguaciones que se practicaron los gastos que estos erogaron para su realización, los cuales conllevan los traslados de los familiares, todos aquellos gastos extrajudiciales que se realizaron para comprobación de hechos y llevar a cabo el proceso respectivo.

En la práctica, la asistencia legal a la víctima no se inicia apenas en la etapa de reparaciones, sino que comienza ante los órganos judiciales nacionales y continúa en las sucesivas instancias del Sistema Interamericano de tutela de los derechos humanos, es decir, en los procedimientos que se siguen ante la Comisión y ante la Corte. Por ende, en el concepto de gastos y costas, para los fines que ahora se examinan, quedan comprendidas tanto las que corresponden a la etapa de acceso a la justicia a nivel nacional como las que se refieren a la justicia a nivel internacional ante dos instancias: la Comisión yla Corte. 


\subsubsection{Gastos ante el Sistema Interamericano, fijados en equidad y de reintegro.}

Los tipos de gastos a que hace alusión la sentencia de 22 de enero de 1999, sobre reparaciones y costas, en el caso Blake Vs. Guatemala, son fijados no obstante que los abogados actuaron de manera gratuita, los siguientes:

\section{i. Gastos: apreciación prudente:}

70. Corresponde a la Corte apreciar prudentemente el alcance específico de dichos gastos, pues si bien los abogados de la parte lesionada actuaron gratuitamente, el Tribunal entiende que aquella debió hacer algunos gastos para el trámite del presente caso ante el Sistema Interamericano de protección de los derechos humanos, en razón de lo cual considera equitativo conceder a la parte lesionada una indemnización de US\$10.000,00 (diez mil dólares de los Estados Unidos de América) como compensación por las erogaciones realizadas en sus gestiones ante dicho sistema. (Caso Blake Vs. Guatemala, párrafo 99).

\section{ii. Reintegro de gastos realizados ante el sistema interamericano.}

b) Además, US\$10.000,00 (diez mil dólares de los Estados Unidos de América) o su equivalente en moneda nacional guatemalteca, a los señores Richard Blake, Mary Blake, Richard Blake Jr. y Samuel Blake, como parte lesionada, por concepto de reintegro de los gastos efectuados en la tramitación del caso ante el sistema interamericano de protección de los derechos humanos, de acuerdo con lo establecido en el párrafo 70 de esta sentencia (Caso Blake Vs. Guatemala, inciso b- punto resolutivo 2).

De lo anterior, podemos observar que el presente rubro esta referido al actuar del juzgador al momento de fijar los gastos efectuados por la parte lesionada en el tramite de un juicio, ya que al momento de establecerlos debe percibir no solamente las costas comprobadas, sino realizar una análisis de las erogaciones que rodearon su tramitación.

\subsubsection{Gastos asociados a la representación:}

81. Es preciso observar que el artículo 23 del Reglamento de la Corte permite a los representantes de las víctimas 0 de sus familiares presentar sus propios argumentos y pruebas en forma autónoma en la etapa de reparaciones ante esta Corte. Este reconocimiento de un locus standi de aquéllos abre la posibilidad de gastos asociados a dicha representación. Ahora bien, en la práctica la asistencia legal a la víctima no se inicia apenas en la etapa de reparaciones, sino comienza ante los órganos judiciales nacionales y continúa en las sucesivas instancias del Sistema Interamericano de tutela de los derechos humanos, es decir, en los procedimientos que se siguen ante la Comisión y ante la Corte, salvo cuando la víctima o sus familiares reciben asistencia jurídica gratuita. Por ende, en el concepto de costas, para los fines que ahora se examinan, quedan comprendidas tanto las que corresponden a la etapa de acceso a la justicia a nivel nacional (cfr. Caso Aloeboetoe y otros, Reparaciones, supra 40, párr. 94; Caso Caballero Delgado y Santana, Reparaciones, supra 40, párr. 47 y punto resolutivo 2; Caso El Amparo, Reparaciones, supra 40, párr. 21 y Caso Neira Alegría y otros, Reparaciones, supra 40, párr. 42), como las que se refieren a la justicia a nivel internacional, que se despliega ante dos instancias: la Comisión y la Corte (Caso Garrido y Baigorria Vs. Argentina, párrafo 81).

Se consideran gastos extrajudiciales a todas aquellas erogaciones realizadas por la parte lesionada fuera de la vía judicial, por ejemplo: gastos para indagar sobre el paradero de una persona, entre otros.

\subsubsection{Gastos extrajudiciales}

Se consideran gastos extrajudiciales a todas aquellas erogaciones realizadas por la parte lesionada fuera de la vía judicial, por ejemplo: gastos para indagar sobre el paradero de una 
persona, entre otros. A continuación presentamos el Caso Blake Vs. Guatemala:

Gastos Extrajudiciales: 48. La Corte ha tenido en consideración que la parte lesionada realizó numerosos viajes, principalmente a la ciudad de Guatemala, con el fin de indagar el paradero del señor Nicholas Blake, ante el encubrimiento de lo ocurrido y la abstención de investigar los hechos por parte de las autoridades guatemaltecas, desde la desaparición de aquél hasta el descubrimiento de sus restos mortales, y que dicha situación motivó gastos por concepto de boletos aéreos, hospedaje, alimentación, pagos por concepto de llamadas telefónicas y otros.

49. Asimismo, la Corte considera que dichos gastos son de carácter extrajudicial, pues, como se ha probado, los familiares del señor Nicholas Blake no acudieron ante los tribunales internos. En razón de lo anterior, la Corte entiende que es procedente ordenar al Estado el pago de los gastos razonables en que incurrió la parte lesionada a partir del 9 de marzo de 1987 (fecha de aceptación por Guatemala de la competencia contenciosa de la Corte), los cuales se estiman, equitativamente, en la cantidad de US $\$ 16.000,00$ (dieciséis mil dólares de los Estados Unidos de América), tomando en cuenta para ello que la sentencia de fondo se refiere solamente a la violación de los artículos 5 y 8 de la Convención Americana.

iii. US $\$ 16.000,00$ (dieciséis mil dólares de los Estados Unidos de América) por concepto de gastos de carácter extrajudicial (Caso Blake Vs. Guatemala, párrafos 48 y 49 ; y numeral iii, del inciso a) del resolutivo 2).

Se consideran gastos extrajudiciales, todas aquellas erogaciones realizadas por la parte lesionada fuera de la vía judicial, por ejemplo: gastos para indagar sobre el paradero de una persona, los de traslado (terrestre 0 aéreo), hospedaje, alimentación, pagos de llamadas telefónicas, entre otros.

\section{VÍCTIMAS}

A continuación exponemos los sujetos jurídicos que son considerados beneficiados con las reparaciones en el caso de violación de derechos humanos, i). La persona que directamente sufrió la violación; ii). Los familiares, iii). Los menores de edad, victimas de violaciones de derechos humanos como; iv). Desaparición forzada de persona; v). Caso de que los familiares no se presenten a recibir la indemnización.

\subsection{Víctima directa, reparaciones}

El señor Suárez Rosero, cuando fue detenido, laboraba para la empresa "Challenge Air Cargo", como encargado de supervisión y control de vuelos y percibía un salario mensual promedio de S/.676.853,35 (seiscientos setenta y seis mil ochocientos cincuenta y tres sucres con treinta y cinco centavos), al cual ya se le ha hecho la deducción impositiva correspondiente. Dicho monto es equivalente aproximadamente a US\$ 449.40 (cuatrocientos cuarenta y nueve dólares de los Estados Unidos de América y que durante su encarcelamiento, y como consecuencia de los tratos crueles, inhumanos y degradantes a que fue sometido, sufrió daños físicos y psicológicos por lo que no ha intentado regresar al ejercicio de su profesión en seguridad aeroportuaria, para la cual se capacitó durante un año, por temor a ser acusado si se presenta algún nuevo evento de tráfico de narcóticos. El día en que fue detenido, el tipo de cambio del sucre, moneda nacional ecuatoriana, con respecto al dólar estadounidense era de S/.1.493,18 (mil cuatrocientos noventa y tres sucres con dieciocho centavos) para la compra y S/.1.519,09 (mil quinientos diecinueve sucres con nueve centavos) para la venta. (Caso Suárez Rosero Vs. Ecuador).

\subsection{Víctimas, familiares}

Las reparaciones que se establezcan en las sentencias deben guardar relación con las violaciones reclamadas, por ello la manifestación 
expresa del pago de gastos que derogaron familiares de la víctima al respecto, la víctima y la Comisión aducen que la Corte ha interpretado el concepto de familia de una manera flexible y amplia y que dicha jurisprudencia es compatible con la de otros órganos internacionales. En razón de lo anterior, consideraron que la Corte debe ordenar reparaciones en beneficio de la misma, por ello la resolución a favor del pago de gastos que se originaron durante y después del proceso, por ello el pago de gastos médicos futuros a los miembros de la Familia (Caso Loayza Tamayo Vs. Perú).

\subsubsection{Reparaciones a familiares}

Respecto a la señora Margarita Ramadán Burbano y a la menor Micaela Suárez Ramadán: Micaela fue concebida en la cárcel y nació el 10 de febrero de 1994, durante el encarcelamiento de su padre; y debido a su discapacidad física, la señora Ramadán Burbano se vio obligada a contratar los servicios de una empleada doméstica y un chofer durante el encarcelamiento del señor Suárez Rosero. (Caso Suárez Rosero Vs. Ecuador)

La Corte Interamericana resuelve en el presente caso las violaciones cometidas por el Estado de violación a la libertad e integridad personal, el derecho a la vida, le negó un recurso efectivo, por lo que esta obligado a indemnizar. Por lo que le corresponde las indemnizaciones a la victima, a sus familiares, por violación de derechos humanos y otras violaciones.

\subsection{Menor de edad, indemnización}

En el caso de la indemnización ordenada en favor de la menor Suárez Ramadán, el Estado constituirá, dentro de un plazo de seis meses a partir de la notificación de esta sentencia, un fideicomiso en una institución financiera ecuatoriana solvente y segura en las condiciones más favorables que permitan la legislación y las prácticas bancarias. Los beneficios derivados de intereses incrementarán el patrimonio, el cual será entregado a Micaela Suárez Ramadán en su totalidad cuando cumpla la mayoría de edad.
En caso de fallecimiento, el derecho se transmitirá a los herederos (Caso SuárezRosero Vs. Ecuador).

\subsection{Víctimas en el caso de desaparición forzada}

El presente caso, expone las indemnizaciones a la víctima directa y a sus familiares respecto de otros hechos:

i). Indemnizaciones con respecto a la víctima: la víctima tenía 22 años al momento de su detención y posterior desaparición, vivía con sus padres y hermanas y se desempeñaba como profesor de matématicas en el Instituto de Estudios Teológicos "Juan XXIII", impartía clases durante doce horas al mes y devengaba un salario mensual de 13.200.000 intis, que en esa época equivalían a US\$ 30.00 (treinta dólares de los Estados Unidos de América) aproxi-madamente. (Caso Castillo Páez Vs. Perú);

ii).- Indemnizaciones con respecto a los familiares de la víctima: Que los familiares conocidos de la víctima son Cronwell Pierre Castillo Castillo, padre, Carmen Rosa Páez Warton, madre, y Mónica Inés Castillo Páez, hermana y que dichos familiares sufrieron daños materiales y morales por la desaparición de Ernesto Rafael Castillo Páez y que los padres de Ernesto Rafael Castillo Páez iniciaron su búsqueda en diversas dependencias policiales y realizaron las gestiones judiciales pertinentes, conforme al derecho interno para localizarlo y, posteriormente, recurrieron al sistema interamericano, todo lo cual generó diversos gastos además que en la actualidad los tres mencionados familiares de Ernesto Rafael Castillo Páez se sostienen con los recursos que les suministra el sistema de seguridad social holandesa (Caso Castillo Páez Vs. Perú);

iii).- Indemnizaciones con respecto a otros hechos: Que la expectativa de vida de un varón de 22 años en el Perú en 1990, era de 71 años y que la remuneración mínima vital de los trabajadores privados en el Perú a partir del 1 de septiembre de 1997 era de 345 soles a demás que el tipo de cambio de la moneda peruana en relación con el dólar de los Estados Unidos de América el 1 de septiembre de 1997, era 
de S/2,65 y que en el Perú existen diversas leyes sobre gratificaciones laborales en los sectores público y privado y, entre ellas, la más favorable al trabajador es la Ley No. 25.139, de 14 de diciembre de 1989, que otorga dos gratificaciones anuales, equivalentes cada una a "la remuneración básica que perciba el trabajador en la oportunidad que corresponda otorgar el beneficio". En el Perú están en vigor la Ley de amnistía No. 26.479 y la Ley No. 26.492, interpretativa de aquélla y que en el Perú está en vigor, igualmente, la Ley No. 26.926, que tipifica los delitos contra la humanidad, entre ellos el genocidio, la desaparición forzada y la tortura.

\section{Reparaciones a familiares.}

Fijar en US\$ 245.021,80 (doscientos cuarenta y cinco mil veintiún dólares de los Estados Unidos de América con ochenta centavos) o su equivalente en moneda nacional, el monto que el Estado del Perú debe pagar en carácter de reparaciones a los familiares del señor Ernesto Rafael Castillo Páez. Estos pagos deberán ser hechos por el Estado de Perú en la proporción y condiciones expresadas en los párrafos 75, 76, 77, 90, 114, 115, 116 y 117 de esta sentencia.

a. Investigar los hechos. Que el Estado del Perú debe investigar los hechos del presente caso, identificar y sancionar a sus responsables y adoptar las disposiciones necesarias en su derecho interno para asegurar el cumplimiento de esta obligación.

b. Que los pagos indicados en los puntos resolutivos 1 y 5 deberán ser efectuados dentro de los seis meses a partir de la notificación de esta sentencia.

c. Que todo pago ordenado en la presente sentencia está exento de cualquier impuesto 0 tasa existente o que llegue a existir en el futuro (Caso Castillo Páez Vs. Perú)

e. Gastos de familiares: traslados, comunicaciones, investigaciones administrativas, visitas a cárceles, hospitales e instituciones públicas, tratamientos médicos.
Igualmente, se ha pedido el resarcimiento de los gastos sufragados por los familiares de Ernesto Rafael Castillo Páez en la búsqueda de éste, lo que incluye traslados, comunicaciones, investigaciones administrativas, visitas a cárceles, hospitales e instituciones públicas, así como gastos correspondientes a tratamientos médicos para la rehabilitación en situaciones de desaparición de un hijo y hermano y erogaciones con motivo del traslado de la familia a Holanda, donde sus integrantes tienen refugio humanitario y asilo político (supra 71.b). Sin embargo, la prueba presentada para respaldar el cálculo no es suficiente ni concluyente, por lo que la Corte considera pertinente otorgar, en equidad, $\left({ }^{10}\right)$ la suma de US\$ 25.000,00 (veinticinco mil dólares de los Estados Unidos de América) por los conceptos mencionados en este rubro (Caso Castillo Páez Vs. Perú).

\section{Víctimas, familiares no se presentan a recibir indemnización.}

Si en el plazo de un año a contar de la notificación de la sentencia alguna de las personas indicadas, no se presentare a recibir el pago que le corresponde, el Estado depositará la cantidad debida en un fideicomiso en dólares de los Estados Unidos de América en su favor, en una institución bancaria de reconocida solvencia en Ecuador y en las condiciones más favorables, de acuerdo con la práctica bancaria. Si después de diez años de constituido el fideicomiso tales personas o sus herederos no hubiesen reclamado los fondos, la cantidad será devuelta al Estado y se considerará cumplida esta sentencia. El Estado puede cumplir sus obligaciones mediante el pago en dólares de los Estados Unidos de América o en una cantidad equivalente en moneda ecuatoriana, utilizando para el cálculo respectivo el tipo de cambio entre ambas monedas que esté vigente en la plaza de Nueva York, Estados Unidos de América, el día anterior al pago (Caso SuárezRosero Vs. Ecuador).

10.- Los gastos por equidad se entienden en el sentido de que se debe de resarcir, a quien sufre una afectación no solo de molestia sino de privación y que al ser-en la mayoría de los casos de actos de molestia o privación- en su mayoría consumados, y en apoyo en la teoría de la equivalencia, por "equidad" equilibrar con una suma liquida el daño causado. 


\section{PAGO}

A continuación exponemos i). El tipo de moneda utilizada para el pago de las reparaciones, ii). El plazo para su pago iii). La exención de impuestos y iv). Pago de salarios caídos.

\subsection{Moneda "dura"}

La Corte adopta como práctica constante en su jurisprudencia la utilización del dólar de los Estados Unidos de América como divisa "dura" para el cálculo de la indemnización compensatoria y ha constatado que esta previsión ha asegurado el valor adquisitivo de los montos ordenados.

Pago en moneda. En cuanto a la "obligación de Pagar los gastos el Estado deberá cumplir sus obligaciones mediante el pago en dólares de los Estados Unidos de América o en una suma equivalente, en dinero efectivo, en moneda nacional peruana, utilizando el tipo de cambio de la moneda nacional peruana con respecto al dólar estadounidense en la plaza de Nueva York, Estados Unidos de América, el día anterior al pago, esto es con la finalidad de cumplir con las disposiciones previamente contraídas entre el Estado Parte y la Convención, las obligaciones que le impone la Convención Americana, la Corte supervisará el cumplimiento de esta sentencia, en el caso particular y dada la variabilidad que presenta la moneda de Perú el Sol; La Corte ha establecido con anterioridad que "una de las vías más accesibles y comunes para lograr ese propósito [...] es la conversión de la suma percibida a una de las llamadas divisas duras" esto quiere decir que el monto a pagar deberá ser emitido por un banco, por un valor específico, generalmente en una moneda dura, Sirve como medio de pago en cualquier país, atendiendo a ello la variabilidad de la Moneda de Perú, esto es con la finalidad de no ocasionar menoscabo y/o detrimento en la cuantificación de los gastos que tiene que cubrir el Estado a la víctima por su actos. La Corte ha adoptado como práctica constante en su jurisprudencia la utilización del dólar de los Estados Unidos de América como divisa "dura" para el cálculo de la indemnización compensatoria y ha constatado que esta previsión ha asegurado el valor adquisitivo de los montos ordenados. (Caso Loayza Tamayo Vs. Perú)

Reparaciones: moneda y mora. Tanto el señor Suárez Rosero como la Comisión indicaron que los pagos que ordenase la Corte podrían ser cuantificados en dólares de los Estados Unidos de América o su equivalente en moneda ecuatoriana. Asimismo, solicitaron que la Corte ordenara al Estado pagar los intereses aplicables en caso de mora. La Comisión solicitó, además, que los pagos fueran hechos dentro de un plazo de tres meses, que estuviesen exentos de impuestos, que se continuara con las investigaciones y que la Corte supervisara el cumplimiento de la sentencia. (Caso Suárez Rosero Vs. Ecuador).

\subsection{Plazo de pago}

Antecedentes: 1.- Plazo de pago de reparaciones. La Corte estima que las pretensiones del señor Suárez Rosero y la Comisión son razonables, con la excepción de aquella, hecha por la Comisión, que se refiere al plazo de pago. En su jurisprudencia constante, el Tribunal ha otorgado a los Estados un plazo de seis meses para dar cumplimiento a las obligaciones establecidas en las sentencias sobre reparaciones. Para dar cumplimiento a la presente sentencia, el Estado deberá ejecutar el pago de las indemnizaciones compensatorias, el reintegro de costas y gastos y la adopción de las otras medidas ordenadas dentro del plazo de seis meses a partir de la notificación de esta sentencia. El pago de las indemnizaciones compensatorias ordenadas en favor del señor Rafael Iván Suárez Rosero y de la señora Margarita Ramadán Burbano será hecho directamente a ellos. Si alguno falleciese, el pago será hecho a sus herederos ${ }^{11}$.

El reintegro de costas y gastos ordenado en favor de los señores Alejandro Ponce Villacís y Richard Wilson será hecho directamente a ellos. Si alguno 
falleciese, el pago deberá ser hecho, en el caso del primero, a sus herederos, y en el caso del segundo, a laAmerican University ${ }^{12}$.

\section{Pago, plazo.}

Para dar cumplimiento a la presente Sentencia, el Estado deberá pagar, en un plazo de seis meses a partir de su notificación, las indemnizaciones establecidas en favor de los familiares de la víctima en dicho carácter, o en el de víctimas, según sea el caso, y si alguno de ellos hubiere fallecido, a sus herederos. El Estado puede cumplir sus obligaciones mediante el pago en dólares estadounidenses o en su equivalente en moneda nacional peruana en dinero efectivo. Para determinar esa equivalencia se utilizará el tipo de cambio del dólar estadounidense y de la moneda peruana en la plaza de Nueva York, Estados Unidos de América, el día anterior al pago.

Si por algún motivo no fuese posible que los beneficiarios de las indemnizaciones reciban las mismas dentro del plazo de seis meses indicado, el Estado deberá consignar dichos montos a su favor en una cuenta o certificado de depósito en una institución financiera solvente y segura en dólares estadounidenses o en su equivalente en moneda nacional peruana y en las condiciones financieras más favorables según permitan la legislación y práctica bancarias. Si al cabo de diez años la indemnización no es reclamada, la suma será devuelta con los intereses devengados al Estado peruano.

Las indemnizaciones indicadas en la presente sentencia no podrán ser objeto de ningún impuesto 0 tasa nacional, provincial o municipal presentes o que puedan decretarse en el futuro. En caso de que el Estado incurriese en mora deberá pagar un interés sobre la suma adeudada que corresponderá al interés bancario de mora en el Perú.

\subsection{Exención de impuestos}

Los pagos ordenados estarán exentos de todo impuesto actualmente existente o que pueda decretarse en el futuro. En caso de que el Estado incurriese en mora deberá pagar, sobre la cantidad adeudada, un interés que corresponderá al interés bancario corriente en el Ecuador durante la mora. En concordancia con su práctica constante y las obligaciones que le impone la Convención Americana, la Corte supervisará el cumplimiento de esta sentencia.

\subsection{Pago de salarios caídos y exención de impuestos}

Ordenar al Estado del Ecuador la aplicación de las siguientes reglas a los pagos determinados en la presente sentencia: el pago de salarios caídos ordenado en el punto resolutivo segundo (apartado a), estará exento de cualquier deducción distinta a la realizada por la Corte cuando hizo el cálculo respectivo, de conformidad con el párrafo 55.A.a de la presente sentencia; y los pagos ordenados estarán exentos de cualquier gravamen o impuesto existentes o que lleguen a existir en el futuro.

\section{CONCLUSIONES}

El tema de gastos tiene su fundamento en la Convención Americana, fundamento, Artículo 63, párrafo 10.; la Responsabilidad internacional; el Reglamento Interno de la CoIDH, artículo 65, párrafo 1, inciso h); y el Daño.

La Gastos son distintas a las costas.

Los tipos de gastos son los siguientes cinco grupos: i). Gastos de traslado; ii). los Gastos médicos (los cuales comprendemos por tratamientos quirúrgicos, pruebas no desvirtuadas, pruebas, falta de sustento, en caso de desaparición forzada de persona y gastos médicos futuros); iii). Los Gastos de apreciación prudente y necesarios y razonables; iv). Gastos en equidad; y v). Gastos procesales y extrajudiciales. 
Las víctimas, son, tanto directamente la víctima, sus Familiares, un régimen especial para menor de edad; y el caso de las víctimas en el caso de desaparición forzada.

Las reglas sobre el pago, existen reglas para tipo de Moneda; el plazo de pago; la exención de impuestos, y el pago de salarios caídos.

\section{BIBLIOHEMEROGRAFÍA}

\section{Sentencias de la Corte Interamericana de Derechos Humanos}

- Caso Blake Vs. Guatemala, sentencia del 22 de enero de 1999.

- Caso Caballero Delgado y Santana, Reparaciones, Sentencia 29 de enero de 1997.

- Caso Castillo Páez Vs. Perú, Sentencia de 27 de noviembre de 1998.

- Caso El Amparo, Reparaciones, Sentencia de 14 de septiembre de 1996.

- Caso Garrido y Baigorria Vs. Argentina, sentencia del 27 de agosto de 1998.

- Caso Godínez Cruz, Indemnización Compensatoria, Sentencia de 21 de julio de 1989.

- Caso Loayza Tamayo Vs. Perú, sentencia 17 de septiembre de 1997.

- Caso Neira Alegría y otros, Reparaciones, Sentencia de 19 de septiembre de 1996.

- Caso Paniagua Morales y otros Vs. Guatemala, sentencia del 25 de mayo de 2001.

- Caso SuárezRoseroVs. Ecuador.

- Caso Velásquez Rodríguez, Indemnización Compensatoria, Sentencia de 21 de julio de 1989 